girders up to $200 \mathrm{ft}$. in clear span, large quays and reservoirs, airport runways and road slabs, tunnels and pipes, pylons and posts, sleepers and piles and innumerable joists, beams and slabs for building work of all kinds. Fig. 5 shows the Esbly Bridge over the Marne by Freyssinet, which is of $250 \mathrm{ft}$. span and is composed of short precast sections connected together by the prestressing cables. The Sclayn Bridge over the Meuse, by Magnel, is a two-span continuous structure formed as a hollow slab with the cables inside: the main spans are each $206 \mathrm{ft}$. long. An excellent example of a large, light prestressed roof structure is now just being completed at London Airport, Heathrow, where main girders over hangar doors are of $150 \mathrm{ft}$. span and the roof beams, $110 \mathrm{ft}$. long and $5 \mathrm{ft}$. deep, have webs only 4 in. thick.

Most of the benefits secured by prestressing spring directly from the elimination of cracking in the concrete. It has already been shown how this secures important economies in the materials, both by enabling the whole concrete section to be used and by enabling both steel and concrete to be worked at higher stresses than formerly. High-strength concrete free from any liability to cracking is clearly suitable for liquid-retaining structures, and many very large reservoirs and pipes of large diameter, etc., have been prestressed.

The presence of a permanent compressive force acting on prestressed members gives them a resilience akin to timber, and this is a characteristic which at once distinguishes prestressed from reinforced concrete and enables the former to be so much more safely handled-or indeed mishandled. Cracks caused by excessive loading close immediately the overload is removed, and it is doubtless this same characteristic which gives prestressed concrete a much higher fatigue resistance, as is so well exemplified in mainline railway sleepers, which have never been successful in ordinary reinforced concrete.

Because the whole section is in compression and, therefore, doing useful work when loaded, a prestressed member has greater stiffness than a reinforced section of the same dimensions ; thus, for the same load, thinner and lighter sections can be employed. This has proved of great value in bridge and girder work, and in round terms has doubled the practicable spans available to reinforced concrete. Lastly, the prestress increases the shear resistance of a beam; if applied in two directions it completely eliminates shear stress. In practice, small prestressed beams require no shear reinforcement.

This all too brief discussion will have indicated the immense possibilities of this powerful technique, which is only on the threshold of development. The next decade may mark swift further strides, and probably the application of prestressing to other materials.

\section{SOFT MAGNETIC MATERIALS IN TELECOMMUNICATIONS}

$\mathrm{D}$

URING the past few years developments in the field of soft magnetic materials have been exceedingly rapid, and it is only necessary to compare the performance of 'Supermalloy.', the various ferrites and the oriented sheet and strip materials, now in common use, with that of the magnetic substances available a quarter of a century ago, to realize how substantial this progress has been. Although some binary nickel-iron alloys had been investigated at the turn of the century, it was not until the comprehensive work of Yensen and of Arnold and Elmen thirty years ago that the possibilities of these alloys became apparent.

It was thought that it would be useful at this time if academic workers, manufacturers and users could be brought together to discuss one another's problems and to hear of the advances made in the different fields. Arrangements were therefore made to hold discussions during April 3-4 at the Post Office Engineering Research Station, Dollis Hill, London, the subject being "Soft Magnetic Materials whose Properties are of Use or Significance in Telecommunications". The meetings were attended by about seventy people from Great Britain and the Continent, who were briefly welcomed by Brigadier L. H. Harris, controller of research, Post Office. Thirty-four papers were presented, and, as these had been available before the meetings opened, discussions were able to start after only a few words from the respective authors. Four sessions were held : Brigadier Harris presided over the first, and the others were in the charge of Profs. W. Sucksmith, L. F. Bates and E. B. Moullin.

With such a restricted field to cover, it would not have been surprising had there been considerable overlapping. But, in fact, authors had approached the subject from so many different angles that it was not always possible to group papers for common discussion. Both theoretical and practical aspects of the subject were covered, and the discussion was lively and informed. It is perhaps an indication of the interest in the subject that a number of enthusiasts went to a continuation meeting held on the morning of April 5 to complete discussions which had had to be cut short on the previous days.

Except for a few papers which dealt with aspects of the matter not generally considered by telecommunications engineers, the authors concentrated on the following main lines : theoretical consequences of domain structure; the mechanism of magnetic losses, particularly 'residual loss'; extremely high permeability materials; powder cores; ferrites; materials having rectangular hysteresis loops; and methods of measurement.

Powder cores, although first suggested by Heaviside, who took out a patent describing their manufacture and use, are still being developed, and the reasons for the superior performance of certain types of carbonyl iron were discussed. The structure of the material is not fully understood; it is peculiar in that it is built up of heterogeneous particles, severely stressed, yet any step taken to purify it and to relieve stress is accompanied by an increase instead of a decrease in magnetic loss. In iron powder cores, decrease in particle size is accompanied by decrease in hysteresis loss, though this does not hold for those nickel-iron powder cores which are heattreated after pressing to develop their magnetic properties. Between the powder cores proper and laminated cores is a laminated powder core developed during the Second World War.

During the past few years industry has had available a new, extremely high permeability material known as 'Supermalloy', which may have an initial permeability as high as 100,000 and a maximum permeability of more than a million. The substance has been shown to be a special case of a family of alloys having nearly zero magnetostriction and anisotropy, which are capable of forming superlattices : the high permeability results from partial 
ordering of the alloy produced by a critical heat treatment. 'Supermalloy' is a ternary nickel-ironmolybdenum alloy; other members of the family contain copper also, but all have comparable magnetic properties.

The effect of impurities in high-permeability materials was discussed both on the basis of a simple theoretical model and with regard to the control which could be effected in manufacture. Surface layers, produced during either rolling or annealing (their exact source is not yet certain), often reduce the permeability of thin laminations of these materials. This effect and the reasons for it were fully discussed.

There is at present a considerable interest in magnetic materials having rectangular hysteresis loops and combining high remanence (more than 95 per cent of the saturation flux density) with low coercivity. The alloys generally used are the siliconirons, nickel-irons and cobalt-nickel-irons. They may be either grain-oriented by cold rolling, followed by suitable heat treatment, or domain-oriented by annealing in a magnetic field, and they present interesting problems in measuring their performance. They are used in magnetic amplifiers, mechanical rectifiers, delay lines and switching devices.

Since the introduction of the complex ferrites, such as zinc-manganese ferrite, by Snoek and his colleagues, they have found many applications in telecommunications when moderately high permeability combined with high resistivity is needed. These materials have opened up new fields of study : their magnetic losses differ in some ways from those of the more normal ferro-magnetics; their high resistivity permits measurements to be made in the microwave region without trouble from eddy currents. Measurements of this nature have shown that, with increasing frequency, permeability tends to unity and resonance effects occur which are consistent with the theoretical work of Néel and his associates.

The customary separation of alternating-current losses into hysteresis, eddy current and 'residual' loss was shown to be unsatisfactory in several ways. Hysteresis loss is difficult to define, and if the power factor due to residual loss varies with frequency (as it certainly does), it cannot be clearly distinguished from eddy-current loss. The residual loss itself may have several components, and an interesting difference came to light between the French and German schools of thought on this subject. A source of loss recognized by both is the rapid migration of impurities within the crystal lattice (Snoek's 'disaccommodation'), giving rise to a strongly temperature-dependent loss. Another loss, less dependent on temperature, is thought by the German workers to be due to thermal effects accompanying magnetostriction, but by the French (and some British) workers to be due to thermally activated movement of domain walls. During discussion of these theories, a crucial experiment (measurement of A.c. loss in the presence of D.c. polarization) was devised for distinguishing between them, and it will shortly be tried on various materials. Although these effects are of technical interest mainly when they appear as A.C. losses, they are also observable at slow changes of D.c. magnetization, and some results were quoted of observations over periods of hours which can to some extent, though not fully, be reconciled with the known A.C. effects.

Several papers reported excess eddy-current losses, usually in material having well-aligned domains, including the rectangular loop materials. The measurements were all at low flux densities, and the effect may, or may not, be the same as the 'eddycurrent anomaly' known in power engineering, for which another explanation was suggested. This excess loss may be the result of concentrating the eddy-current loss in the regions close to domain walls instead of distributing it uniformly through the material. A further suggestion was that non-uniform flux gives rise not only to excess eddy-current loss, but also residual loss.

Specialized methods of measurement have been developed to study such problems as the variation of permeability through the thickness of strips of high-permeability nickel-iron alloys. Two laboratories have made measurements at frequencies of the order of $10 \mathrm{Mc} / \mathrm{s}$. at which only the surface layers of the material are effective; other studies have been made by measurement after electropolishing of the strips and by metallographic examination of cross-sections. Some differences between results may be due to differences between British, French and German material, and exchanges of specimens have been arranged.

Several papers diseussed the harmonic distortion and the intermodulation produced by magnetic cores. Some materials can produce intermodulation but not harmonics, so that the definition of 'linearity' requires close attention. Experiments have shown that the hysteresis loss due to two superposed signals may be less than that due to the two separately; this, however, can be explained by well-known theory.

A criticism of much work reported (not only at this meeting) by physicists and engineers is that they cannot describe adequately the materials with which they are working. They are generally dependent for supplies on industrialists who do not always realize how much help they could give by describing precisely the samples of materials which they so often generously give to academic workers for research. It is, for example, often difficult to decide from published work just what nickel-iron alloy has been used; the same name may describe different alloys in different countries, and, in fact, different alloys in one country at different times.

\section{O BITUARY}

\section{Sir Charles Inglis, O.B.E., F.R.S.}

Sir Charles Edward INGLIS, emeritus professor of mechanical sciences in the University of Cambridge, who died on April 19 at the age of seventy-six, was probably the greatest teacher of engineering of our day. His powers as a lecturer were unrivalled, as many, outside Cambridge, will know from the lectures he gave before the local centres of the professional engineering institutions throughout Great Britain. Especially to an academic audience, he gave the appearance that what he most wanted to do at that moment was to give that lecture to that particular audience. He loved teaching, and much of the success of his lectures was due to the enormous amount of work he devoted to preparing them; then he spoke fluently and to all appearances without a note.

His power of attracting the love and admiration of all his undergraduates was the greatest of all his 